\title{
Attenuated Activity across Multiple Cell Types and Reduced Monosynaptic Connectivity in the Aged Perirhinal Cortex
}

\author{
(1)Andrew P. Maurer, ${ }^{1,2 *}$ (ISara N. Burke, ${ }^{1,3 *}$-Kamran Diba, ${ }^{4}$ and ${ }^{\circ}$ Carol A. Barnes ${ }^{5,6,7}$ \\ ${ }^{1}$ McKnight Brain Institute, Department of Neuroscience, ${ }^{2}$ Department of Biomedical Engineering, and ${ }^{3}$ Institute on Aging, University of Florida, \\ Gainesville, Florida 32611, ${ }^{4}$ Department of Psychology, University of Wisconsin-Milwaukee, Milwaukee, Wisconsin 53201, and ${ }^{5}$ Evelyn F. McKnight Brain \\ Institute, ${ }^{6}$ Division of Neural Systems Memory and Aging, and ${ }^{7}$ Departments of Psychology, Neurology and Neuroscience, University of Arizona, Tucson, \\ Arizona 85721
}

The perirhinal cortex (PER), which is critical for associative memory and stimulus discrimination, has been described as a wall of inhibition between the neocortex and hippocampus. With advanced age, rats show deficits on PER-dependent behavioral tasks and fewer PER principal neurons are activated by stimuli, but the role of PER interneurons in these altered circuit properties in old age has not been characterized. In the present study, PER neurons were recorded while rats traversed a circular track bidirectionally in which the track was either empty or contained eight novel objects evenly spaced around the track. Putative interneurons were discriminated from principal cells based on the autocorrelogram, waveform parameters, and firing rate. While object modulation of interneuron firing was observed in both young and aged rats, PER interneurons recorded from old animals had lower firing rates compared with those from young animals. This difference could not be accounted for by differences in running speed, as the firing rates of PER interneurons did not show significant velocity modulation. Finally, in the aged rats, relative to young rats, there was a significant reduction in detected excitatory and inhibitory monosynaptic connections. Together these data suggest that with advanced age there may be reduced afferent drive from excitatory cells onto interneurons that may compromise the wall of inhibition between the hippocampus and cortex. This circuit dysfunction could erode the function of temporal lobe networks and ultimately contribute to cognitive aging.

Key words: hippocampus; medial temporal lobe; object field; place field; rat

Significance Statement

We report that lower firing rates observed in aged perirhinal cortical principal cells are associated with weaker interneuron activity and reduced monosynaptic coupling between excitatory and inhibitory cells. This is likely to affect feedforward inhibition from the perirhinal to the entorhinal cortex that gates the flow of information to the hippocampus. This is significant because cognitive dysfunction in normative and pathological aging has been linked to hyperexcitability in the aged CA3 subregion of the hippocampus in rats, monkeys, and humans. The reduced inhibition in the perirhinal cortex reported here could contribute to this circuit imbalance, and may be a key point to consider for therapeutic interventions aimed at restoring network function to optimize cognition.

\section{Introduction}

The perirhinal cortex (PER), which is critical for higher-order sensory representations (Buckley and Gaffan, 1997; Murray and

Received Feb. 23, 2017; revised July 25, 2017; accepted Aug. 4, 2017.

Author contributions: A.P.M., S.N.B., and C.A.B. designed research; A.P.M. and S.N.B. performed research; K.D. contributed unpublished reagents/analytic tools; A.P.M., S.N.B., and K.D. analyzed data; A.P.M., S.N.B., and C.A.B. wrote the paper.

This work was supported by the McKnight Brain Research Foundation and National Institutes of Health Grants AG003376, NS054465, NS070464, AG049722, AG049411, AG055544, and MH109548. We thank Kim Bohne, Jie Wang, Michael Montgomery, Michelle Carroll, and Luann Snyder for help in completing this manuscript.

*A.P.M. and S.N.B. contributed equally to this work.

The authors declare no competing financial interests.

Correspondence should be addressed to Carol A. Barnes, Evelyn F. McKnight Brain Institute, Life Sciences North Building, Room 362, University of Arizona, Tucson, AZ 85724. E-mail: carol@nsma.arizona.edu.
Bussey, 1999; Burwell et al., 2004; Bartko et al., 2007; KholodarSmith et al., 2008; Murray and Wise, 2012) and memory (Buffalo et al., 1999; Barker et al., 2007), is vulnerable to the effects of advanced age (Burke et al., 2012b, 2014; Ryan et al., 2012). Moreover, this structure is one of the first brain areas to undergo pathological alterations in preclinical Alzheimer's disease (Braak and Braak, 1991; Braak et al., 1993; Khan et al., 2014; Hirni et al., 2016; Krumm et al., 2016). These data suggest that understanding the mechanisms of PER dysfunction in normal aging and disease could provide novel insights into the neurobiology of age-associated cognitive decline. 
Although there is no loss of PER neurons with age (Rapp et al., 2002), a number of studies have reported altered biochemistry (Liu et al., 2008a, 2008c, 2009; Moyer et al., 2011) and physiological profiles (Burke et al., 2014) in aged PER principal neurons. Specifically, aged PER principal cells are not as responsive to object stimuli compared with young PER neurons, and a larger portion of PER cells in old animals are quiescent during behavior relative to young animals (Burke et al., 2014). Declines in PER principal cell firing rates could arise from a loss of excitatory afferent drive either from adjacent sensory association cortical areas, such as area TE, or from recurrent excitatory synapses within the PER. Alternatively, reduced principal cell activity in the aged PER could be due to enhanced inhibitory control. In fact, age-related imbalances between inhibition and excitation in the hippocampus (Yassa et al., 2011a; Spiegel et al., 2013; Thomé et al., 2016) and the prefrontal cortex (Insel et al., 2012; McQuail et al., 2012, 2015; Bañuelos et al., 2014; Beas et al., 2017) have been linked to impairments in spatial memory and executive functions, respectively. To date, however, limited data are available regarding whether age-related declines in PER principal cell activity results from enhanced inhibitory control versus reduced excitatory drive.

Because inhibitory interneurons within the PER project locally as well as to the superficial layers of the entorhinal cortex (Pinto et al., 2006; Apergis-Schoute et al., 2007), these cells might be particularly important for gating communication across the medial temporal lobe. In fact, PER interneuron activity may be directly involved in modulating the excitatory drive from layers II and III of the entorhinal cortex to the hippocampus. The current experiment examined activity patterns of PER interneurons and principal cell-interneuron interactions from young and aged rats trained to traverse a circular track for food reward. In some behavioral conditions, the track was empty while in other conditions the track contained three-dimensional objects. Putative interneurons were isolated from principal cells based on the autocorrelogram, waveform parameters, and firing rates (Barthó et al., 2004) to interrogate potential age-associated firing-rate differences in these two cellular populations, as well as to examine the impact of advanced age on excitatory-inhibitory monosynaptic coupling. Understanding how the integrity of the PER microcircuit is affected in old animals may provide new insights regarding the mechanisms of age-related cognitive decline and medial temporal lobe dysfunction.

\section{Materials and Methods}

Subjects and behavioral training. All behavioral procedures were performed in accordance with the National Institutes of Health guidelines for rodents and with protocols approved by the University of Arizona Institutional Animal Care and Use Committee. Electrophysiological studies were conducted on six young (8-10 months old) and six aged (24-27 months old) Fischer-344 male rats. All rats participated in these experiments in pairs of one young rat and one aged rat such that a single old-young pair arrived in the colony in the same batch of animals, went through identical behavior procedures on the same days, and underwent surgical implantation within $24 \mathrm{~h}$ of each other. The rats were housed individually and maintained on a 12:12 light/dark cycle. All electrophysiological recordings took place during the dark phase of the rats' light/ dark cycle.

During electrophysiological recordings, the animals were food deprived to $\sim 85 \%$ of their ad libitum weight and trained to run on a circular track ( $\sim 335 \mathrm{~cm}$ in circumference) in both the counterclockwise and clockwise directions for food reinforcement located at either end of a barrier on the track. The food reward was a mixture of rat food pellets made soft by soaking them in water, applesauce, and the diet supplement
Ensure and given in a small plastic food dish $(4 \times 4 \mathrm{~cm})$ at two positions that marked the completion of one lap on opposite sides of the barrier. This barrier marked the point at which the rat was required to turn around and run in the opposite direction. During all electrophysiological recording sessions, rats were required to run $\geq 20$ laps (10 in the counterclockwise direction and 10 in the clockwise direction) during two distinct episodes of behavior. In some epochs, the track was bare, and in the others the track contained eight distinct objects that were made of plastic, wood or glass and no more that $7 \mathrm{~cm}$ across in any dimension. Each track-running epoch was flanked by a rest period in which the rat was placed in a towel-lined pot located in a position central to the circumference of the track. Thus, the activity of PER neurons was monitored during an initial rest session (before behavior); during the first epoch of track running; during a second rest session after epoch 1 , which was $20 \mathrm{~min}$; during a second epoch of track running; and then finally during a third rest period. Data from the rest periods were used to assess firing stability across the entire recording session. Several diodes were mounted on the head stage to allow position tracking during rest and track running. The position of the diode array was detected by a TV camera placed directly above the experimental apparatus and recorded with a sampling frequency of $60 \mathrm{~Hz}$. The sampling resolution was such that a pixel was $\sim 0.3 \mathrm{~cm}$.

For all conditions in which objects were placed on the track, the objects were fixed in place using Velcro. Thus, rats could actively explore, rear, and climb on the objects without displacing them. Additionally, during all rest periods, the objects were removed from the track so that the rat could not see them during the intervening delay period.

Surgical procedures. Surgery was conducted according to National Institutes of Health guidelines for rodents and protocols approved by the University of Arizona Institutional Animal Care and Use Committee. Before surgery, the rats were administered penicillin G (30,000 U, i.m., in each hindlimb) to combat infection. During surgical implantation, the rats were maintained under anesthesia with isoflurane administered at doses ranging from 0.5 to $2.5 \%$.

All rats were implanted with a "hyperdrive" manipulator device that held an array of 14 separately moveable tetrode recording probes (Wilson and McNaughton, 1993, 1994; Gothard et al., 1996). Each hyperdrive consisted of 14 drive screws coupled by a nut to a guide cannula. Twelve of these cannulae contained tetrodes (McNaughton et al., 1983a; Recce and O'Keefe, 1989), four-channel electrodes constructed by twisting together four strands of insulated $13 \mu \mathrm{m}$ nichrome wire (H.P. Reid). Two additional tetrodes had their individual wires shorted together, and the shorted tetrode with the least cellular activity was used as an indifferent reference. A full turn of the screw advanced the tetrode $318 \mu \mathrm{m}$ and all tetrodes were lowered between 4.0 and $6.0 \mathrm{~mm}$ ventral to the surface of brain. The 14 guide cannulae were arranged in two linear columns of seven each such that the configuration of tetrodes spanned $\sim 2 \mathrm{~mm}$ from the anterior to posterior position. This permitted sampling of neurons from a greater extent of the PER and enabled more precise matching of tetrode number to track and lesion location for histological verification. Sites for all tetrode recordings included in the current analyses were verified histologically and have been reported previously (Burke et al., 2014).

The implant was cemented in place with dental acrylic anchored by small screws. Immediately after surgery, all tetrodes were lowered $\sim 1 \mathrm{~mm}$ into the cortex, and rats were orally administered $26 \mathrm{mg}$ of acetaminophen (Children's Tylenol Elixir) for analgesia. Oral administration of acetaminophen was continued for 3-5 d after surgery.

In all rats, recordings were made from the middle to caudal PER region (between 4.0 and $6.5 \mathrm{~mm}$ posterior to bregma, $6.0 \mathrm{~mm}$ lateral to bregma, and angled $14^{\circ}$ toward the midline) in areas 35 and 36 from both the deep and superficial layers. Following experimental procedures, $20 \mu \mathrm{A}$ of DC current was administered to each tetrode. One to 2 weeks following microlesioning, rats were given a fatal dose of pentobarbital and perfused with $4 \%$ paraformaldehyde (Gage et al., 2012). Brains were extracted and soaked in a $30 \%$ sucrose solution for 1 week or until they sank. Tissue was then frozen with dry ice and the area under the cranial implant was coronally sectioned at $40 \mu \mathrm{m}$ with a cryostat. Sections were directly mounted to superfrost slides and dried overnight in a fume hood. Finally, tissue was Nissl-stained and the tetrode location was verified. In most 
cases, the tetrode tracks were not parallel to the plane of sectioning and tracks had to be followed over several adjacent slides. In these cases, the section in which the lesion was the largest was considered the approximate location. Only the units recorded from tetrodes histologically verified to be in the PER were used in the current analyses and neurons recorded from other brain regions (e.g., ventral CA1 or area TE of the inferotemporal cortex) were excluded. Most tetrodes were in area 36 of the PER, but in two young and two aged rats four tetrodes reached dorsal area 35 (i.e., the transentorhinal cortex). Moreover, in the young rats, neurons were recorded from both layer V and layers II/III, but for the aged rats only one rat had tetrodes in layers II/III, and all the other single-unit recordings were from neurons in layer V. Notably, there were no differences in any of the parameters investigated in this paper between PER subregions 36 and 35 and deep versus superficial cortical layers. Therefore, data were combined for all analyses and it is unlikely that differences in the cortical layers sampled could account for observed age effects ( $p>0.2$ for all comparisons).

Neurophysiology. After surgery, tetrodes were lowered into the PER over several weeks. The neutral reference electrode was advanced with other tetrodes and when an area of cortex was reached that did not record any unit activity, it was not moved again. The four channels of each tetrode were attached to a 50-channel unity-gain head stage (Neuralynx). A multiwire cable connected the head stage to digitally programmable amplifiers (Neuralynx). The spike signals were amplified by a factor of $1000-5000$, bandpass-filtered between $600 \mathrm{~Hz}$ and $6 \mathrm{kHz}$, and transmitted to the Cheetah Data Acquisition system (Neuralynx). Signals were digitized at $32 \mathrm{kHz}$, and events that reached a predetermined threshold were recorded for $1 \mathrm{~ms}$. Spikes were sorted off-line on the basis of the amplitude and principal components from the four tetrode channels by means of a semiautomatic clustering algorithm (KlustaKwik; author: K.D. Harris). The resulting classification was corrected and refined manually with custom-written software (MClust; author: A.D. Redish, University of Minnesota; updated by S.L. Cowen, University of Arizona and D.R. Euston, University of Lethbridge), resulting in a spike-train time series for each of the well isolated cells. Data were pooled from six young and six aged rats across 64 recording sessions, with each rat contributing $\geq 4$ datasets and no single animal having $>7$ datasets included in the current analyses. For each rat, only datasets obtained from nonadjacent recording days were included in the current analyses. This procedure, along with the repositioning of tetrodes each day, ensured that a single neuron was not included in an analysis multiple times.

Analyses and statistics. Once spike sorting was completed, the isolation distance and L-ratio value were calculated for each cluster (SchmitzerTorbert et al., 2005). The $\mathrm{L}$ ratio is the degree that a cluster separates from other spikes recorded on the same tetrode normalized by the total number of spikes for a given cluster. A lower $\mathrm{L}$ ratio is indicative of better separation (Schmitzer-Torbert et al., 2005). The isolation distance estimates how far cluster spikes are from other spikes recorded on the same tetrode (Harris et al., 2001). Higher isolation distance therefore corresponds to better separation and a reduced probability of contamination from noise or spikes from other neurons. We implemented a threshold such that only clusters with a $\mathrm{L}$ ratio $<0.20$ and an isolation distance $>32.75$ were included in the current analyses. These values were selected as they correspond to the means of clusters qualitatively rated as having good separation and low amounts of noise contamination. Furthermore, only neurons that had stable firing rates between the rest epoch preceding behavior and a final rest epoch were included in the analyses. In both age groups, neither principal cells nor interneurons have a significant change in firing rate between the prebehavioral and postbehavioral rest episodes ( $p>0.03$ for all comparisons).

Putative principal cells and interneurons were identified by means of their waveform characteristics and autocorrelogram features (Leonard et al., 1987; Barthó et al., 2004; Sirota et al., 2008). Specifically, neocortical principal cells tend to have autocorrelograms with peaks at 3-6 ms followed by an exponential decay, which is indicative of "bursting" cells, or an autocorrelogram with an exponential rise from 1 to tens of milliseconds, indicative of regular-spiking neurons. In contrast, the autocorrelograms of putative interneurons are not as fast decaying or slow rising as those of pyramidal neurons (Barthó et al., 2004).
Table 1. Database and cluster quality metrics

\begin{tabular}{|c|c|c|c|c|c|c|}
\hline & \multicolumn{3}{|c|}{ Principal cells } & \multicolumn{3}{|c|}{ Interneurons } \\
\hline & \# & L ratio & $\begin{array}{l}\text { Isolation } \\
\text { distance }\end{array}$ & \# & L ratio & $\begin{array}{l}\text { Isolation } \\
\text { distance }\end{array}$ \\
\hline Young & 262 & $0.027( \pm 0.002)$ & $83.03( \pm 9.59)$ & 69 & $0.023( \pm 0.003)$ & $93.32( \pm 9.25)$ \\
\hline Aged & 352 & $0.019( \pm 0.002)$ & $78.41( \pm 4.16)$ & 72 & $0.028( \pm 0.004)$ & $82.03( \pm 3.43)$ \\
\hline
\end{tabular}

To determine putative excitatory or inhibitory monosynaptic connections, all possible pairwise cross-correlograms (CCGs) were calculated with a bin size of $1 \mathrm{~ms}$ and convolved with a $5 \mathrm{~ms}$ Gaussian window (Stark and Abeles, 2009). Any pairs with $<2.5$ spike counts per CCG bin within $\pm 12 \mathrm{~ms}$ were excluded from further analysis. For excitatory putative monosynaptic connections, peaks within $3 \mathrm{~ms}$ time lag were classified as significant based on a Poisson approximation and $p$ value $<0.05$. The criteria for a putative inhibitory connection was a significant trough within $3 \mathrm{~ms}$ based on a Poisson approximation and $p$ value $<0.05$. Moreover, for the connection to be considered inhibitory, the slower time course of inhibitory action needed to be accounted for by requiring that a neighboring bin exhibit a significant trough at $p<0.01$ for the Poisson approximation. This procedure produced a reduced dataset of pairs of interest. To assess significance nonparametrically in this subset that met the preliminary criteria for a putative monosynaptic connection, we performed $10005 \mathrm{~ms}$ jitters and $10001 \mathrm{~ms}$ jitters on the spike trains of the population of nonreference cells and calculated global and local 5\% significance bands for CCGs of cell pairs for both jitter timescales (Fujisawa et al., 2008; Diba et al., 2014). CCGs of cell pairs from the reduced dataset that exhibited a significant peak (relative to $1 \mathrm{~ms}$ jitter) between 1 and $3 \mathrm{~ms}$ were categorized as putative excitatory connections. CCGs of cell pairs from the reduced dataset that exhibited a significant trough (relative to $5 \mathrm{~ms}$ jitter) between 1 and $3 \mathrm{~ms}$ were categorized as putative inhibitory connections. CCGs of cell pairs from the reduced dataset that exhibited a significant peak at $0 \mathrm{~ms}$ (relative to $1 \mathrm{~ms}$ jitter) were categorized as "zero lag" (millisecond synchronous) pairs.

To calculate firing rates by running velocity of the rat, position information was convoluted over 41 frames $(\sim 683 \mathrm{~ms})$. The running speed was then calculated as the position displacement between adjacent frames. Speed occupancy distributions were then computed as the number of speed samples per $10 \mathrm{~cm} / \mathrm{s}$ bin, with $3-12 \mathrm{~cm} / \mathrm{s}$ speeds in the first bin. Speed bins were cut off at $42 \mathrm{~cm} / \mathrm{s}$ due to low sampling at higher velocities in the aged rats. For each recorded neuron, the number of spikes that occurred within each speed interval was computed. The firing rate versus speed function was then calculated from the ratios of these two distributions.

While basic waveform characteristics were examined on individual cells to ensure that neuron subtypes were correctly classified, for all other statistical tests comparing firing-rate differences and proportions of monosynaptically connected cells between young and aged rats, statistics were run on the mean for each animal. This eliminates the potential for inflated statistical power when nested variables (e.g., multiple observations from a single rat) are treated as independent samples (Aarts et al., 2014).

\section{Results}

Waveform characteristics of principal cells and interneurons

Table 1 shows the number of neurons that met inclusion criteria for the current analyses and the mean isolation distances and $\mathrm{L}$ ratios for principal cells and interneurons recorded from young and aged rats. Age comparisons for cluster quality are also shown in Table 1. A two-way ANOVA comparing the L ratios across cell types and age groups showed no main effect of age $\left(F_{(1,751)}=\right.$ $0.33, p=0.57$ ) or of cell type (principal cells vs interneuron; $\left.F_{(1,751)}=0.71, p=0.40\right)$. When the isolation distances of all clusters were compared between the different cells types and age groups, there was also not a significant main effect age $\left(F_{(1,751)}=\right.$ $0.59, p=0.44)$ or of cell type $\left(F_{(1,751)}=0.45, p=0.51\right)$. Together, these data suggest that cluster quality was comparable across cell types for both the young and aged rats. 
A

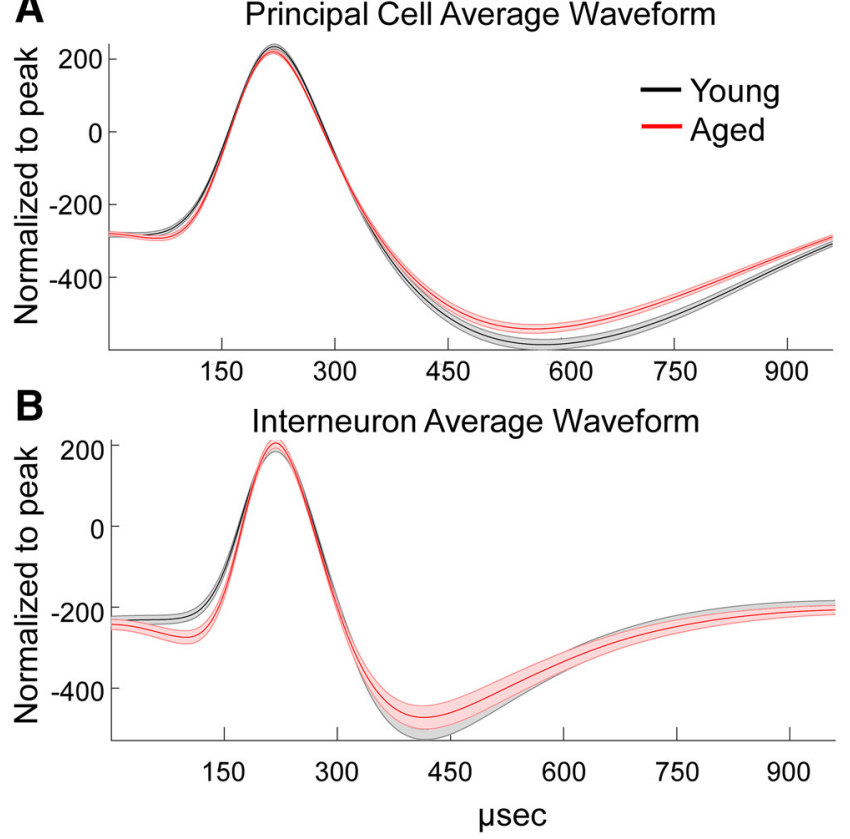

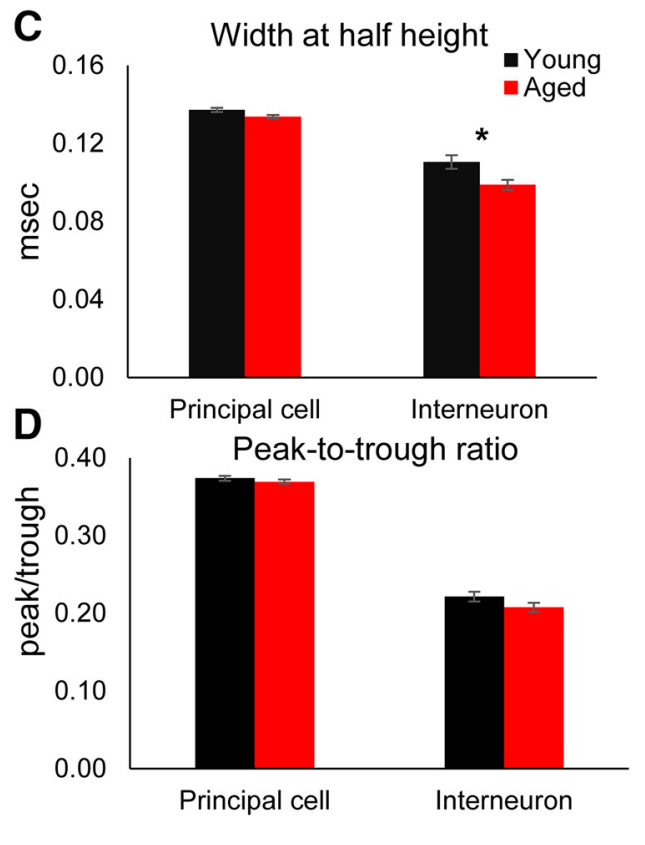

Figure 1. Principal cell and interneuron waveform characteristics in young and aged rats. $\boldsymbol{A}, \boldsymbol{B}$, The mean and \pm 1 SEM waveform plotted over a $1 \mathrm{~ms}$ time window in young (red) and aged (black) rats for $(\boldsymbol{A})$ principal cells, and $(\boldsymbol{B})$ interneurons. In both panels, all waveforms were normalized to the peak. $\boldsymbol{C}$, The mean spike width at half-height $(y$-axis) for principal cells and interneurons in young and aged rats. As expected, the peaks in interneurons were significantly narrower those in principal cells $\left(F_{(1,751)}=285.65, p<0.001\right)$. Moreover, there was also a significant effect of age $\left(F_{(1,751)}=17.47, p<0.001\right)$ and an age by cell-type interaction $\left(F_{(1,751)}=5.11, p<0.03\right)$. Post hoc analysis indicated that the aged rats had narrower interneuron spike widths relative to those of the young rats $(p<0.001)$, but principal waveforms did not significantly differ between age groups $(p=0.13)$. $D$, The mean peak-to-trough ratios ( $y$-axis) for principal cells and interneurons in young and aged rats. Principal cells had significantly greater peak-to-trough amplitude ratios compared with those of interneurons $\left(F_{(1,751)}=10.78, p<0.001\right)$, but this did not differ as a function of age $\left(F_{(1,751)}=3.52, p=0.06\right)$. Error bars represent \pm 1 SEM and asterisks indicate $p<0.05$.

Figure 1 shows the average waveforms for putative principal cells (Fig. 1A) and interneurons (Fig. $1 B$ ) recorded from young (black) and aged rats (red). When the average spike width at the half peak was compared across cell types and age groups (Fig. 1C), there was a significant main effect of cell type $\left(F_{(1,751)}=285.65\right.$, $p<0.001$ ) such that the interneurons had significantly narrower spike widths relative to principal cells. There was also a significant main effect of age $\left(F_{(1,751)}=17.47, p<0.001\right)$ and a significant interaction effect of age and cell type $\left(F_{(1,751)}=5.12, p<0.03\right)$ on spike width. Post hoc analysis indicated that this was due to the aged rats having narrower interneuron spike widths relative to the young rats $(p<0.001)$, while the width of principal waveforms was not significantly different between age groups $(p=0.13)$.

Analysis of the peak-to-trough ratio between the different cell types also revealed differences between putative principal cells and interneurons (Fig. 1D). Specifically, the peak-to-trough ratio was significantly greater in the principal cells compared with interneurons $\left(F_{(1,751)}=10.78, p<0.001\right)$. The peak-to-trough ratio did not, however, vary significantly as a function of age $\left(F_{(1,751)}=3.52, p=0.06\right)$, nor was there a significant interaction effect between cell type and age $\left(F_{(1,751)}=0.97, p=0.32\right)$. This indicates that for both cell-type classifications, young and aged rats had similar peak-to-trough ratios, which is distinct from what has been reported for cells in CA1 (Landfield and Pitler, 1984; Pitler and Landfield, 1990; Landfield, 1996) and CA3 of the hippocampus (Simkin et al., 2015).

\section{The effects of age and objects on interneuron firing rate}

A previous study observed reduced firing rates of PER principal cells in aged rats compared with young rats (Burke et al., 2014), and a lower proportion of cells active in response to object stimuli (Burke et al., 2012b, 2014). One potential explanation for re- duced PER excitability in old animals could be an increase in local inhibitory control. To test this hypothesis directly, the firing rates of putative interneurons and principal cells across laps around the track were compared when novel objects were on the track compared with the when the track was empty. Figure $2 A, B$ shows the firing rates across laps in the different track running conditions for principal cells and interneurons, respectively. Since rats ran in both the clockwise and counterclockwise directions, the objects were novel during laps 1 and 2 and became more familiar with subsequent laps. To evaluate whether firing rates of PER interneurons showed any sort of response decrement as objects went from novel to familiar, the firing rates during the first two laps were compared with the rates during laps 7 and 8 with repeated-measures ANOVA with the between-subjects factor of age for conditions with novel objects and when the track was empty. Consistent with what has been reported for PER principal cells (Burke et al., 2014), the firing rates of interneurons did not significantly change between early and late laps of track running $\left(F_{(1,18)}=2.49 ; p=0.13\right)$. Moreover, the firing rates across laps did not significantly interact with condition (objects vs no objects; $\left.F_{(1,18)}=0.56, p=0.46\right)$, or age group $\left(F_{(1,18)}=1.77, p=0.22\right)$. The main effect of age, however, was significant $\left(F_{(1,18)}=8.69, p<0.01\right)$, such that PER interneurons recorded from young rats had significantly higher firing rates than those of the aged rats. Finally, there was not a significant main effect of condition (objects vs no objects) on interneuron firing rate $\left(F_{(1,18)}=2.39, p<0.14\right)$.

\section{Velocity modulation in PER interneuron and principal cell firing rates}

One potential explanation for interneuron firing-rate differences between old and young rats could arise from differences in running velocity. Specifically, the firing rates of cells in the hippocampus 
A

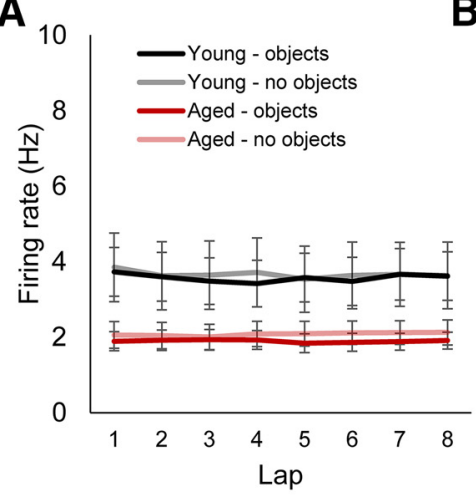

B

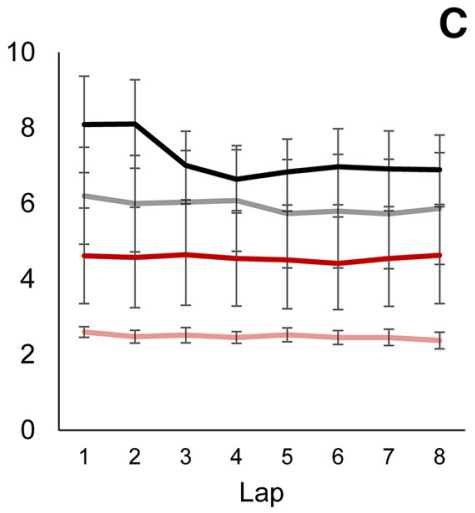

C

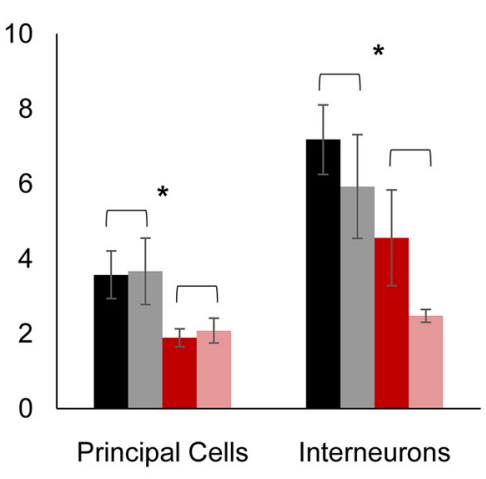

Figure 2. Firing rate by lap in young and aged rats. $\boldsymbol{A}, \boldsymbol{B}$, The mean firing ( $y$-axis) as a function of lap for $(\boldsymbol{A})$ principal cells and $(\boldsymbol{B})$ interneurons in conditions in which novel objects were placed around the track (dark) or the track was empty (light). In both young and aged rats, the firing rate did not systematically change over laps or as objects went from being novel to familiar ( $p>0.1$ for all comparisons). $C$, The overall average firing rates of principal cells and interneurons across the entire recording session in young and aged rats. There was a significant effect of age group on overall firing rate $\left(F_{(1,18)}=8.69, p<0.01\right)$, with the neurons recorded from aged rats having lower firing rates compared with the cells of young animals. This age difference was observed in both principal cells and interneurons. Error bars represent \pm 1 SEM and asterisks indicate $p<0.05$.

A

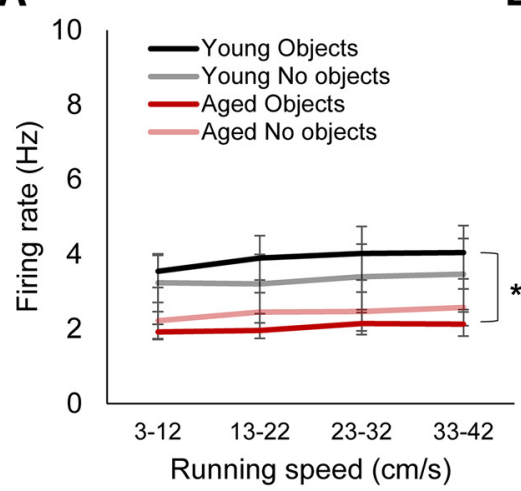

B

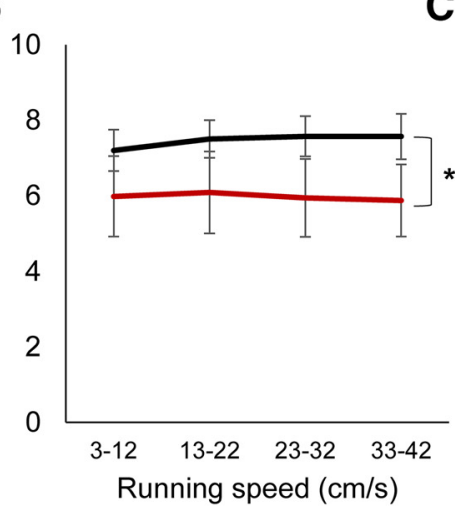

C

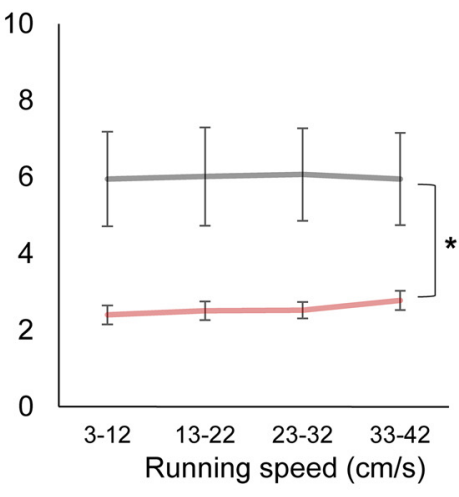

Figure 3. Firing rate by running speed in young and aged rats. $\boldsymbol{A}-\boldsymbol{C}$, The mean firing ( $\boldsymbol{y}$-axis) as a function of running speed for $(\boldsymbol{A})$ principal cells and ( $\boldsymbol{B}, \boldsymbol{C})$ interneurons in conditions in which novel objects were placed around the track (dark) or the track was empty (light). In both young and aged rats, firing rate was not significantly modulated by running speed ( $p>0.1$ for all comparisons). However, when velocity was matched across behavioral conditions and objects were on the track, interneuron firing rates were significantly higher $\left(F_{(1,21)}=4.47, p<0.05\right)$. Error bars represent \pm 1 SEM and asterisks indicate $p<0.05$.

(McNaughton et al., 1983b; Maurer et al., 2005) and medial entorhinal cortex (Kropff et al., 2015) are strongly modulated by the animal's running velocity. Thus, if PER interneuron activity is higher when rats move at faster velocities, the overall slower running speeds observed in aged rats (Shen et al., 1997; Burke et al., 2014) could result in observed firing-rate differences due to behavioral rather than physiological mechanisms. To examine this possibility, the interneuron firing rates across a range of velocities $(0-39 \mathrm{~cm} / \mathrm{s})$ in which adequate sampling occurred in both age groups was quantified. Consistent with a previous report (Burke et al., 2014), the variance in PER principal cell firing rates was not significantly explained by running speed (Fig. $3 A ; r_{(98)}^{2}=0.04$, $p=0.53)$. Similarly, PER interneuron firing-rate variance could also not significantly be explained by running velocity (Fig. $3 B, C$; $\left.r_{(98)}^{2}=0.03, p=0.86\right)$. This was confirmed when firing rates were compared across velocity with repeated-measures ANOVA, with the between-subjects factors of age group and behavioral condition: velocity did not have a significant effect on firing rate $\left(F_{(3,63)}=0.63\right.$, $p=0.60)$. Additionally, velocity did not significantly interact with age group $\left(F_{(3,63)}=0.26, p=0.86\right)$ or behavioral condition $\left(F_{(3,63)}=0.17, p=0.92\right)$.

When velocities were matched between young and aged rats, the interneuron firing rate was still significantly reduced in the aged rats, compared with young rats $\left(F_{(1,21)}=4.21, p<0.05\right)$. These data indicate that differences in running speed cannot account for the reduced interneuron firing rates in aged rats compared with young rats. Interestingly, when velocities were matched, there was also a significant main effect of condition on interneuron firing rate $\left(F_{(1,21)}=4.47, p<0.05\right)$ such that interneuron firing rates were higher when objects were on the track relative to when the track was empty, but this did not significantly interact with age $\left(F_{(1,21)}=0.22, p<0.64\right)$. Notably, when velocity was not matched across age groups and behavioral conditions, there was not a significant effect of objects versus no objects on interneuron firing rate (Fig. 2C), although there was a trend for higher interneuron firing rates when objects were on the track. Matching across velocity bins may have reduced the variability in firing so that the effect of objects on increasing the interneuron firing rate was statistically detectable.

\section{Principal cell-interneuron monosynaptic coupling in young and aged rats}

The observation that aged PER interneurons showed reduced firing rates compared with young PER interneurons is contrary to the notion that age-associated declines in PER principal cell activity arise from enhanced inhibition. In fact, because both cells 

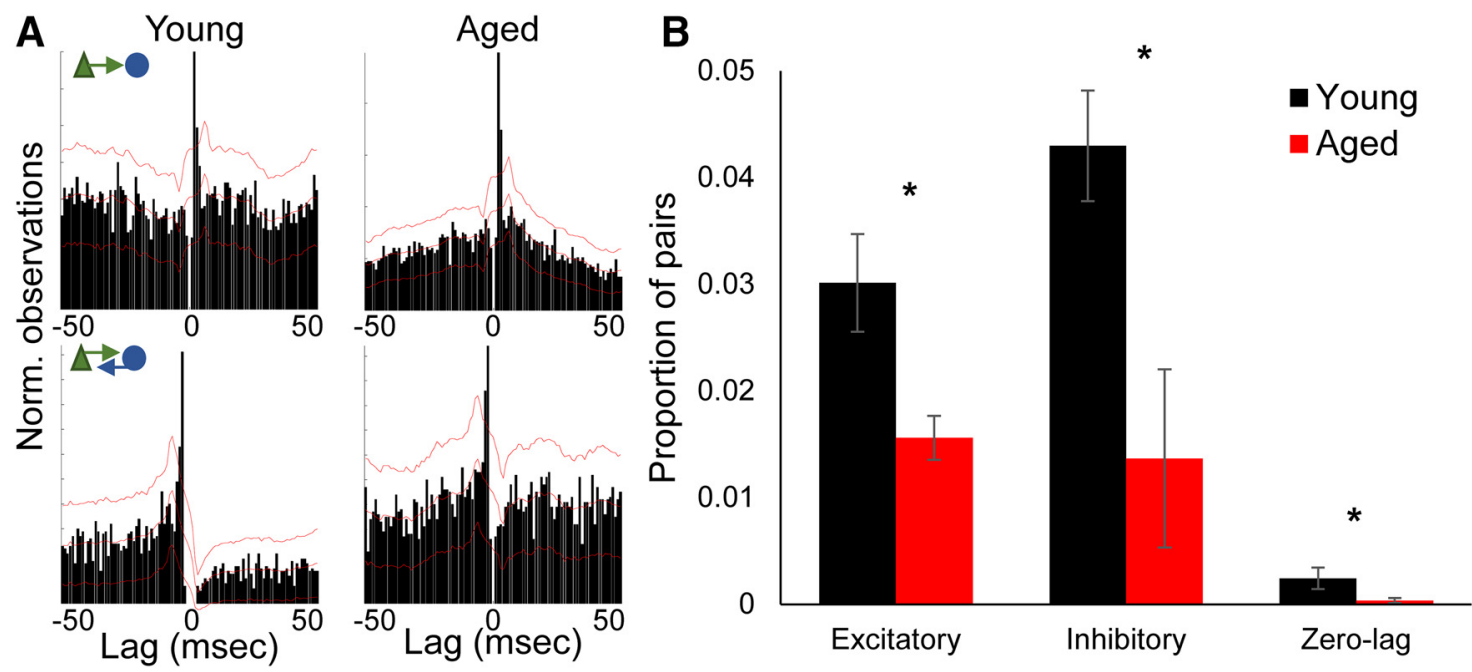

Figure 4. Putative monosynaptic connections in young and aged rats. $\boldsymbol{A}$, CCGs of representative examples of excitatory (top) and inhibitory (bottom) putative monosynaptic connections for a young (left) and an aged (right) rat. $Y$-axes are the normalized number of observations within each 1 ms time bin over a 100 ms window (X-axes). $\boldsymbol{B}$, Proportion of putative monosynaptic connections from all possible cell pairs in young and aged rats for excitatory, inhibitory, and zero-lag connections. Aged rats had significantly lower proportions of detected monosynaptic cell pairs compared with young animals $\left(F_{(1,9)}=12.00, p<0.01\right)$. Error bars represent \pm 1 SEM and asterisks indicate $p<0.05$.

types in the PER show lower activity levels in aged animals, it is conceivable that lower principal cell activity in old animals decreases the afferent drive onto interneurons, resulting in lower firing rates across the PER neuron population. To further explore the possibility that afferent drive within the local PER circuit is affected by advanced age, the proportion of cell pairs with a putative monosynaptic connection in the young versus aged PER was quantified. Short-latency narrow peaks or valleys in the CCGs of neuronal pairs have been considered the neurophysiological hallmark of monosynaptic connections (Csicsvari et al., 1998; Barthó et al., 2004; Fujisawa et al., 2008; Diba et al., 2014). The statistical significance of these peaks and valleys can then be tested against a nonparametric spike jitter distribution to identify those cell pairs that have short-term scale dynamics indicative of a monosynaptic connection. This approach was implemented to test for the proportion of significant excitatory and inhibitory putative monosynaptic connections in young versus aged rats for all simultaneously recorded cell pairs that met the L-ratio and isolation-distance thresholds.

Figure $4 A$ shows representative examples of excitatory (top) and inhibitory (bottom) putative monosynaptic connections for a young (left) and an aged (right) rat. Repeated-measures ANOVA testing differences in the proportion of putative monosynaptic connections, with the within-subjects factor of type of connection (excitatory, inhibitory, or zero lag) and the between-subjects factor of age, showed a significant effect of connection type on the proportion of detected monosynaptic cell pairs (Fig. $4 B ; F_{(2,18)}=$ 22.66, $p<0.001)$. Planned orthogonal contrasts revealed that while there was no significant difference between the proportion of inhibitory and excitatory connections $(p=0.29$; difference contrast), the proportion of zero-lag connections was significantly less compared with the other two types $(p<0.05$; difference contrast). In fact, in two young rats and four aged rats, no zero-lag connections were detected. This is distinct from the hippocampus in which up to $12 \%$ of all possible interneuron cell pairs show synchronous zero-lag connections (Diba et al., 2014).

Age also had a significant effect on the proportion of detected monosynaptic cell pairs $\left(F_{(1,9)}=12.00, p<0.01\right)$, with the aged rats, compared with young animals, having fewer connected cells (Fig. 4B). The degree to which the proportion of putative monosyn- aptic connections decreased with advanced age did not significantly differ between excitatory and inhibitory connections $(p=0.15)$. This observation suggests that both excitatory and inhibitory PER synapses are vulnerable in old animals.

To determine whether the detected connections in old and young rats had similar strength, excitatory efficacy was defined for all principal cell-interneuron connections as the probability that the interneuron would fire within $3 \mathrm{~ms}$ following principal cell activity. Synchronous zero-lag cell pairs were excluded from this analysis due to the limited subset of rats in which this connection type was detected. In young rats, the mean excitatory efficiency was 0.017 ( \pm 0.002 SEM), and in aged rats the excitatory efficiency was 0.012 ( \pm 0.001 SEM). Mann-Whitney $U$ test indicated that there was a significant age effect on excitatory efficiency $(p<0.02)$. Together, these data indicate that even when a putative monosynaptic connection is detected in an aged rat, it is not as effective at driving the postsynaptic cell to fire when compared with synaptic connections of young rats.

\section{Discussion}

The current study examined the firing rates of principal cells and interneurons, as well as the intrinsic connectivity of the PER in young and aged rats. Consistent with a previous report (Burke et al., 2014) and with human imaging data (Ryan et al., 2012), the firing rates of aged principal cells in the PER were reduced compared with those recorded from young animals (Fig. 2A). The novel insight from these data was that decreased activity in aged PER principal cells was associated with several physiological alterations in interneurons. First, PER interneurons in aged rats had lower firing rates compared with interneurons recorded from young animals (Fig. $2 B, C$ ). Importantly, this firing-rate difference was observed both when novel objects were on the track and when the track was empty. Moreover, the age-related firing-rate decline could not be accounted for by differences in running speed between the age groups (Fig. 3), as PER interneuron firing rate was not velocity modulated. Interestingly, while principal cells do not show firing-rate differences between object and no-object conditions (Burke et al., 2014; Fig. 3A), in the present data, the interneuron firing rate in both young and aged rats was higher when objects were present (Fig. $3 B, C$ ). It has 
previously been shown that PER principal cells have diffuse spiking, with low spatial information content, when objects are not present (Burwell et al., 1998; Burke et al., 2012a, 2014; Bos et al., 2017), and reorganize activity patterns to coincide with discrete spatial areas near objects when stimuli are added to an environment (Burke et al., 2012a, 2014; Deshmukh et al., 2012). The observation that the interneuron firing rate is increased under conditions with objects suggests a mechanism by which interneuron activity increases to modulate principal spike timing and reduce activity not related to a specific stimulus.

The final novel observation in the current data was that monosynaptic connectivity between principal cells and interneurons (Fig. 4) was reduced. These observations suggest that with advanced age there is either a reduced afferent drive onto excitatory cells or an intrinsic inability of these cells to fire in response to stimuli, which aggregates across the circuit by failing to engage inhibitory interneurons. These data also suggest that in advanced age the inhibitory wall between the neocortex and entorhinal cortices imposed by the PER (Pelletier et al., 2004; de Curtis and Paré, 2004; Pinto et al., 2006; Apergis-Schoute et al., 2007) may break down. Such a shift in PER circuit dynamics with age could contribute to the hyperexcitability that has been observed in the CA3 subregion of the hippocampus in old rats (Wilson et al., 2005; Robitsek et al., 2015), monkeys (Thomé et al., 2016), and humans (Yassa et al., 2011a, 2011b; Bakker et al., 2012, 2015). In fact, it has recently been observed that aged behaviorally impaired rats have higher proportions of active cells in both CA3 and in layer II lateral entorhinal cortical neurons that project to the hippocampus (Maurer et al., 2017). Because PER interneurons synapse on layer II of the entorhinal cortex (Pinto et al., 2006; Apergis-Schoute et al., 2007), reduced interneuron activity could promote hyperactivity in the lateral entorhinal cortex that then aggregates across the circuit contributing to CA3 hyperexcitability.

The finding that excitatory principal cells and inhibitory interneurons both have lower firing rates may appear somewhat paradoxical. The circuitry between the neocortex and PER, as well as its intrinsic connectivity, however, may promote this overall blunting of cell firing when one or more aspects of the network become compromised in old age. Specifically, input into the PER from ventral temporal association cortex (TE) synapses onto both excitatory principal neurons and interneurons (Pinto et al., 2006), along with stimulation of TE, produces a large IPSP in the adjacent area 36 of PER that diminishes the initial EPSP (Biella et al., 2001; Martina et al., 2001; Unal et al., 2012). Thus, age-related declines in afferent drive from TE to PER would decrease activity in both excitatory and inhibitory cell populations. Moreover, local excitatory drive from principal neurons onto interneurons would be attenuated (Marshall et al., 2002; Barthó et al., 2004; Maurer et al., 2006). This effect is then compounded in old animals that show reduced monosynaptic connectivity within the local PER circuit. In young animals, longitudinal projections within the PER are extensive (Burwell and Amaral, 1998; Lavenex et al., 2004) and primarily excitatory (Martina et al., 2001), suggesting that the intact PER circuit is biased toward distributed input. In fact, paired $\theta$-burst stimulation of nearby adjacent cortical input leads to long-term depression, while the same stimulation applied to distributed neocortical inputs to PER leads to long-term potentiation (Unal et al., 2012). Thus, with old age a disruption in a single stream of neocortical input could impair the integration of distributed input patterns necessary to produce synaptic modification within PER circuits.

In addition to the potential circuit mechanism of lower PER activity levels in the aged brain described above, a number of known age-related biochemical alterations could also contribute to the observed declines in both excitatory and inhibitory cell firing. Old rats have lower expression of protein for the NR2 and NR1 NMDA receptor subunits within the PER (Liu et al., 2008b). While it is not known whether this occurs ubiquitously across the principal cell and interneuron populations, reductions in this excitatory receptor in old animals could limit the engagement of PER cells in response to stimuli even if the afferent drive from cortical association areas was not altered with age. Moreover, NMDA receptor loss with age could impair plasticity mechanisms known to support associative learning and recognition memory (Warburton et al., 2005; Winters and Bussey, 2005; Barker and Warburton, 2008; 2015; Banks et al., 2012), both of which are impaired in old animals (Burke et al., 2010; 2011; Hernandez et al., 2015).

An additional, but not mutually exclusive, mechanism for altered firing rates in the PER could be the loss of calbindin, which has been shown to occur in old animals (Moyer et al., 2011). In the absence of pathology, there is no overall loss of neurons with age in the PER, and the expression of calcium buffers often used as markers for interneurons, such a parvalbumin and calretinin, do not appear to be altered (Moyer et al., 2011; Thomé et al., 2016). In contrast to parvalbumin and calretinin, the calciumbinding protein calbindin is primarily expressed by excitatory principal cells in the PER and the levels of this protein are attenuated in old animals (Moyer et al., 2011). While the exact cellular functions of calbindin in the PER remain to be determined, calbindin knock-out mice have reduced synaptic facilitation and frequency potentiation in the hippocampus (Klapstein et al., 1998). Thus, a reduction in calbindin in the PER could shift the synaptic modification window away from enhancement, which could ultimately produce lower firing rates and contribute to impaired monosynaptic coupling. In support of this idea, calbindin knock-out mice also have been shown to have a reduction in the maintenance of long-term potentiation (Westerink et al., 2012).

Although it is counterintuitive that reduced interneuron activity would be associated with decreased rather than increased principal cell activity, the changes in circuit output that accompanies perturbation in interneurons are often not linearly predictable (Buzsáki, 2006). In fact, because interneurons are known to organize spike activity and promote synchronous firing through rebound excitation (Cobb et al., 1995), it is conceivable that decreased interneuron activity could lead to reduced synchrony and to lower firing rates in the principal cells. If PER interneuron activity acts to synchronize input onto principal cells within this region to facilitate stimulus-related activity, lower interneuron activity could partially account for why PER principal cells in aged animals, compared with such cells in young rats, are not as responsive to objects. Optogenetic modulation of PER interneurons would provide the ability to directly test this hypothesis, allowing determination of whether altering interneuron activity would change behavior in a manner analogous to aged animals.

\section{Conclusions}

The PER integrates multisensory information with spatial and temporal representations in the hippocampus to support new memory formation (Young et al., 1997; Barense et al., 2005; Bussey et al., 2005; Eichenbaum et al., 2007; Reagh and Yassa, 2014). Declines in accurate sensory representations supported by the PER occur in aging (Burke et al., 2010, 2011; Ryan et al., 2012) and were recently recognized as a cognitive vulnerability 12 years before a clinical diagnosis of Alzheimer's disease (Hirni et al., 2016). While the mechanisms that underlie these early perceptual/ 
encoding deficits remain poorly understood, the current data further highlight the vulnerability of PER circuits in aging by identifying age-related reductions in activity levels of both excitatory principal cell and interneuron populations as potential mechanism for declines in PER-dependent behaviors. In addition to the documented behavioral deficits on PER-dependent behaviors, this brain region is among the first structures to exhibit tau pathology in Alzheimer's disease. Thus, it is possible that age-associated vulnerability in PER circuits renders this structure more prone to disease-related pathology. A consequence of lower overall activity levels in the PER could be an erosion of the wall of inhibition between the cortex and hippocampus (Martina et al., 2001; de Curtis and Paré, 2004; Pinto et al., 2006; ApergisSchoute et al., 2007), which could contribute to the imbalance between excitation and inhibition that is widely reported with advancing age (Wilson et al., 2005; Yassa et al., 2011a, 2011b; Bakker et al., 2012, 2015; Thomé et al., 2016). Together, these data suggest that therapeutic targets aimed at improving PER circuit function could potentially improve cognitive outcomes in the elderly as well as slow the progression of Alzheimer's disease.

\section{References}

Aarts E, Verhage M, Veenvliet JV, Dolan CV, van der Sluis S (2014) A solution to dependency: using multilevel analysis to accommodate nested data. Nat Neurosci 17:491-496. CrossRef Medline

Apergis-Schoute J, Pinto A, Paré D (2007) Muscarinic control of long-range GABAergic inhibition within the rhinal cortices. J Neurosci 27:40614071. CrossRef Medline

Bakker A, Krauss GL, Albert MS, Speck CL, Jones LR, Stark CE, Yassa MA, Bassett SS, Shelton AL, Gallagher M (2012) Reduction of hippocampal hyperactivity improves cognition in amnestic mild cognitive impairment. Neuron 74:467-474. CrossRef Medline

Bakker A, Albert MS, Krauss G, Speck CL, Gallagher M (2015) Response of the medial temporal lobe network in amnestic mild cognitive impairment to therapeutic intervention assessed by fMRI and memory task performance. Neuroimage Clin 7:688-698. CrossRef Medline

Banks PJ, Bashir ZI, Brown MW (2012) Recognition memory and synaptic plasticity in the perirhinal and prefrontal cortices. Hippocampus 22:20122031. CrossRef Medline

Bañuelos C, Beas BS, McQuail JA, Gilbert RJ, Frazier CJ, Setlow B, Bizon JL (2014) Prefrontal cortical GABAergic dysfunction contributes to agerelated working memory impairment. J Neurosci 34:3457-3466. CrossRef Medline

Barense MD, Bussey TJ, Lee AC, Rogers TT, Davies RR, Saksida LM, Murray EA, Graham KS (2005) Functional specialization in the human medial temporal lobe. J Neurosci 25:10239-10246. CrossRef Medline

Barker GR, Warburton EC (2008) NMDA receptor plasticity in the perirhinal and prefrontal cortices is crucial for the acquisition of long-term object-in-place associative memory. J Neurosci 28:2837-2844. CrossRef Medline

Barker GR, Warburton EC (2015) Object-in-place associative recognition memory depends on glutamate receptor neurotransmission within two defined hippocampal-cortical circuits: a critical role for AMPA and NMDA receptors in the hippocampus, perirhinal, and prefrontal cortices. Cereb Cortex 25:472-481. CrossRef Medline

Barker GR, Bird F, Alexander V, Warburton EC (2007) Recognition memory for objects, place, and temporal order: a disconnection analysis of the role of the medial prefrontal cortex and perirhinal cortex. J Neurosci 27:2948-2957. CrossRef Medline

Barthó P, Hirase H, Monconduit L, Zugaro M, Harris KD, Buzsáki G (2004) Characterization of neocortical principal cells and interneurons by network interactions and extracellular features. J Neurophysiol 92:600-608. CrossRef Medline

Bartko SJ, Winters BD, Cowell RA, Saksida LM, Bussey TJ (2007) Perirhinal cortex resolves feature ambiguity in configural object recognition and perceptual oddity tasks. Learn Mem 14:821-832. CrossRef Medline

Beas BS, McQuail JA, Bañuelos C, Setlow B, Bizon JL (2017) Prefrontal cortical GABAergic signaling and impaired behavioral flexibility in aged F344 rats. Neuroscience 345:274-286. CrossRef Medline
Biella G, Uva L, de Curtis M (2001) Network activity evoked by neocortical stimulation in area 36 of the guinea pig perirhinal cortex. J Neurophysiol 86:164-172. Medline

Bos JJ, Vinck M, van Mourik-Donga LA, Jackson JC, Witter MP, Pennartz CMA (2017) Perirhinal firing patterns are sustained across large spatial segments of the task environment. Nat Commun 8:15602. CrossRef Medline

Braak H, Braak E (1991) Neuropathological stageing of Alzheimer-related changes. Acta Neuropathol 82:239-259. CrossRef Medline

Braak H, Braak E, Bohl J (1993) Staging of Alzheimer-related cortical destruction. Eur Neurol 33:403-408. Medline

Buckley MJ, Gaffan D (1997) Impairment of visual object-discrimination learning after perirhinal cortex ablation. Behav Neurosci 111:467-475. CrossRef Medline

Buffalo EA, Ramus SJ, Clark RE, Teng E, Squire LR, Zola SM (1999) Dissociation between the effects of damage to perirhinal cortex and area TE. Learn Mem 6:572-599. CrossRef Medline

Burke SN, Wallace JL, Nematollahi S, Uprety AR, Barnes CA (2010) Pattern separation deficits may contribute to age-associated recognition impairments. Behav Neurosci 124:559-573. CrossRef Medline

Burke SN, Wallace JL, Hartzell AL, Nematollahi S, Plange K, Barnes CA (2011) Age-associated deficits in pattern separation functions of the perirhinal cortex: a cross-species consensus. Behav Neurosci 125:836847. CrossRef Medline

Burke SN, Maurer AP, Hartzell AL, Nematollahi S, Uprety A, Wallace JL, Barnes CA (2012a) Representation of three-dimensional objects by the rat perirhinal cortex. Hippocampus 22:2032-2044. CrossRef Medline

Burke SN, Hartzell AL, Lister JP, Hoang LT, Barnes CA (2012b) Layer V perirhinal cortical ensemble activity during object exploration: a comparison between young and aged rats. Hippocampus 22:2080-2093. CrossRef Medline

Burke SN, Maurer AP, Nematollahi S, Uprety A, Wallace JL, Barnes CA (2014) Advanced age dissociates dual functions of the perirhinal cortex. J Neurosci 34:467-480. CrossRef Medline

Burwell RD, Amaral DG (1998) Perirhinal and postrhinal cortices of the rat: interconnectivity and connections with the entorhinal cortex. J Comp Neurol 391:293-321. CrossRef Medline

Burwell RD, Shapiro ML, O’Malley MT, Eichenbaum H (1998) Positional firing properties of perirhinal cortex neurons. Neuroreport 9:3013-3018. CrossRef Medline

Burwell RD, Saddoris MP, Bucci DJ, Wiig KA (2004) Corticohippocampal contributions to spatial and contextual learning. J Neurosci 24:38263836. CrossRef Medline

Bussey TJ, Saksida LM, Murray EA (2005) The perceptual-mnemonic/feature conjunction model of perirhinal cortex function. Q J Exp Psychol B 58:269-282. CrossRef Medline

Buzsáki G (2006) Rhythms of the brain. New York: Oxford UP.

Cobb SR, Buhl EH, Halasy K, Paulsen O, Somogyi P (1995) Synchronization of neuronal activity in hippocampus by individual GABAergic interneurons. Nature 378:75-78. CrossRef Medline

Csicsvari J, Hirase H, Czurko A, Buzsáki G (1998) Reliability and state dependence of pyramidal cell-interneuron synapses in the hippocampus: an ensemble approach in the behaving rat. Neuron 21:179-189. CrossRef Medline

de Curtis M, Paré D (2004) The rhinal cortices: a wall of inhibition between the neocortex and the hippocampus. Prog Neurobiol 74:101-110. CrossRef Medline

Deshmukh SS, Johnson JL, Knierim JJ (2012) Perirhinal cortex represents nonspatial, but not spatial, information in rats foraging in the presence of objects: comparison with lateral entorhinal cortex. Hippocampus 22: 2045-2058. CrossRef Medline

Diba K, Amarasingham A, Mizuseki K, Buzsáki G (2014) Millisecond timescale synchrony among hippocampal neurons. J Neurosci 34:1498414994. CrossRef Medline

Eichenbaum H, Yonelinas AP, Ranganath C (2007) The medial temporal lobe and recognition memory. Annu Rev Neurosci 30:123-152. CrossRef Medline

Fujisawa S, Amarasingham A, Harrison MT, Buzsáki G (2008) Behaviordependent short-term assembly dynamics in the medial prefrontal cortex. Nat Neurosci 11:823-833. CrossRef Medline

Gage GJ, Kipke DR, Shain W (2012) Whole animal perfusion fixation for rodents. J Vis Exp pii:3564. CrossRef Medline

Gothard KM, Skaggs WE, Moore KM, McNaughton BL (1996) Binding of 
hippocampal CA1 neural activity to multiple reference frames in a landmark-based navigation task. J Neurosci 16:823-835. Medline

Harris KD, Hirase H, Leinekugel X, Henze DA, Buzsáki G (2001) Temporal interaction between single spikes and complex spike bursts in hippocampal pyramidal cells. Neuron 32:141-149. CrossRef Medline

Hernandez AR, Maurer AP, Reasor JE, Turner SM, Barthle SE, Johnson SA, Burke SN (2015) Age-related impairments in object-place associations are not due to hippocampal dysfunction. Behav Neurosci 129:599-610. CrossRef Medline

Hirni DI, Kivisaari SL, Krumm S, Monsch AU, Berres M, Oeksuez F, Reinhardt J, Ulmer S, Kressig RW, Stippich C, Taylor KI (2016) Neuropsychological markers of medial perirhinal and entorhinal cortex functioning are impaired twelve years preceding diagnosis of Alzheimer's dementia. J Alzheimers Dis 52:573-580. CrossRef Medline

Insel N, Patron LA, Hoang LT, Nematollahi S, Schimanski LA, Lipa P, Barnes CA (2012) Reduced gamma frequency in the medial frontal cortex of aged rats during behavior and rest: implications for age-related behavioral slowing. J Neurosci 32:16331-16344. CrossRef Medline

Khan UA, Liu L, Provenzano FA, Berman DE, Profaci CP, Sloan R, Mayeux R, Duff KE, Small SA (2014) Molecular drivers and cortical spread of lateral entorhinal cortex dysfunction in preclinical Alzheimer's disease. Nat Neurosci 17:304-311. CrossRef Medline

Kholodar-Smith DB, Allen TA, Brown TH (2008) Fear conditioning to discontinuous auditory cues requires perirhinal cortical function. Behav Neurosci 122:1178-1185. CrossRef Medline

Klapstein GJ, Vietla S, Lieberman DN, Gray PA, Airaksinen MS, Thoenen H, Meyer M, Mody I (1998) Calbindin-D28k fails to protect hippocampal neurons against ischemia in spite of its cytoplasmic calcium buffering properties: evidence from calbindin-D28k knockout mice. Neuroscience 85:361-373. CrossRef Medline

Kropff E, Carmichael JE, Moser MB, Moser EI (2015) Speed cells in the medial entorhinal cortex. Nature 523:419-424. CrossRef Medline

Krumm S, Kivisaari SL, Probst A, Monsch AU, Reinhardt J, Ulmer S, Stippich C, Kressig RW, Taylor KI (2016) Cortical thinning of parahippocampal subregions in very early Alzheimer's disease. Neurobiol Aging 38:188196. CrossRef Medline

Landfield PW (1996) Aging-related increase in hippocampal calcium channels. Life Sci 59:399-404. CrossRef Medline

Landfield PW, Pitler TA (1984) Prolonged Ca2+-dependent afterhyperpolarizations in hippocampal neurons of aged rats. Science 226:1089-1092. CrossRef Medline

Lavenex P, Suzuki WA, Amaral DG (2004) Perirhinal and parahippocampal cortices of the macaque monkey: intrinsic projections and interconnections. J Comp Neurol 472:371-394. CrossRef Medline

Leonard BJ, McNaughton BL, Barnes CA (1987) Suppression of hippocampal synaptic plasticity during slow-wave sleep. Brain Res 425:174-177. CrossRef Medline

Liu P, Gupta N, Jing Y, Zhang H (2008a) Age-related changes in polyamines in memory-associated brain structures in rats. Neuroscience 155:789796. CrossRef Medline

Liu P, Smith PF, Darlington CL (2008b) Glutamate receptor subunits expression in memory-associated brain structures: regional variations and effects of aging. Synapse 62:834-841. CrossRef Medline

Liu P, Chary S, Devaraj R, Jing Y, Darlington CL, Smith PF, Tucker IG, Zhang $\mathrm{H}$ (2008c) Effects of aging on agmatine levels in memory-associated brain structures. Hippocampus 18:853-856. CrossRef Medline

Liu P, Jing Y, Zhang H (2009) Age-related changes in arginine and its metabolites in memory-associated brain structures. Neuroscience 164:611628. CrossRef Medline

Marshall L, Henze DA, Hirase H, Leinekugel X, Dragoi G, Buzsáki G (2002) Hippocampal pyramidal cell-interneuron spike transmission is frequency dependent and responsible for place modulation of interneuron discharge. J Neurosci 22:RC197. Medline

Martina M, Royer S, Paré D (2001) Propagation of neocortical inputs in the perirhinal cortex. J Neurosci 21:2878-2888. Medline

Maurer AP, Vanrhoads SR, Sutherland GR, Lipa P, McNaughton BL (2005) Self-motion and the origin of differential spatial scaling along the septotemporal axis of the hippocampus. Hippocampus 15:841-852. CrossRef Medline

Maurer AP, Cowen SL, Burke SN, Barnes CA, McNaughton BL (2006) Phase precession in hippocampal interneurons showing strong func- tional coupling to individual pyramidal cells. J Neurosci 26:13485-13492. CrossRef Medline

Maurer AP, Johnson SA, Hernandez AR, Reasor J, Cossio DM, Fertal KE, Mizell JM, Lubke KN, Clark BJ, Burke SN (2017) Age-related changes in lateral entorhinal and CA3 neuron allocation predict poor performance on object discrimination. Front Syst Neurosci 11:49. CrossRef Medline

McNaughton BL, O'Keefe J, Barnes CA (1983a) The stereotrode: a new technique for simultaneous isolation of several single units in the central nervous system from multiple unit records. J Neurosci Methods 8:391397. CrossRef Medline

McNaughton BL, Barnes CA, O'Keefe J (1983b) The contributions of position, direction, and velocity to single unit activity in the hippocampus of freely-moving rats. Exp Brain Res 52:41-49. Medline

McQuail JA, Bañuelos C, LaSarge CL, Nicolle MM, Bizon JL (2012) GABA(B) receptor GTP-binding is decreased in the prefrontal cortex but not the hippocampus of aged rats. Neurobiol Aging 33:1124.e1-1124.e12. CrossRef Medline

McQuail JA, Frazier CJ, Bizon JL (2015) Molecular aspects of age-related cognitive decline: the role of GABA signaling. Trends Mol Med 21:450 460. CrossRef Medline

Moyer JR Jr, Furtak SC, McGann JP, Brown TH (2011) Aging-related changes in calcium-binding proteins in rat perirhinal cortex. Neurobiol Aging 32:1693-1706. CrossRef Medline

Murray EA, Bussey TJ (1999) Perceptual-mnemonic functions of the perirhinal cortex. Trends Cogn Sci 3:142-151. CrossRef Medline

Murray EA, Wise SP (2012) Why is there a special issue on perirhinal cortex in a journal called Hippocampus? The perirhinal cortex in historical perspective. Hippocampus 22:1941-1951. CrossRef Medline

Pelletier JG, Apergis J, Paré D (2004) Low-probability transmission of neocortical and entorhinal impulses through the perirhinal cortex. J Neurophysiol 91:2079-2089. CrossRef Medline

Pinto A, Fuentes C, Paré D (2006) Feedforward inhibition regulates perirhinal transmission of neocortical inputs to the entorhinal cortex: ultrastructural study in guinea pigs. J Comp Neurol 495:722-734. CrossRef Medline

Pitler TA, Landfield PW (1990) Aging-related prolongation of calcium spike duration in rat hippocampal slice neurons. Brain Res 508:1-6. CrossRef Medline

Rapp PR, Deroche PS, Mao Y, Burwell RD (2002) Neuron number in the parahippocampal region is preserved in aged rats with spatial learning deficits. Cereb Cortex 12:1171-1179. CrossRef Medline

Reagh ZM, Yassa MA (2014) Object and spatial mnemonic interference differentially engage lateral and medial entorhinal cortex in humans. Proc Natl Acad Sci U S A 111:E4264-E4273. CrossRef Medline

Recce ML, O'Keefe J (1989) The tetrode: an improved technique for multiunit extracellular recording. Soc Neurosci Abstr 15:1250.

Robitsek J, Ratner MH, Stewart T, Eichenbaum H, Farb DH (2015) Combined administration of levetiracetam and valproic acid attenuates agerelated hyperactivity of CA3 place cells, reduces place field area, and increases spatial information content in aged rat hippocampus. Hippocampus 25:1541-1555. CrossRef Medline

Ryan L, Cardoza JA, Barense MD, Kawa KH, Wallentin-Flores J, Arnold WT, Alexander GE (2012) Age-related impairment in a complex object discrimination task that engages perirhinal cortex. Hippocampus 22:19781989. CrossRef Medline

Schmitzer-Torbert N, Jackson J, Henze D, Harris K, Redish AD (2005) Quantitative measures of cluster quality for use in extracellular recordings. Neuroscience 131:1-11. CrossRef Medline

Shen J, Barnes CA, McNaughton BL, Skaggs WE, Weaver KL (1997) The effect of aging on experience-dependent plasticity of hippocampal place cells. J Neurosci 17:6769-6782. Medline

Simkin D, Hattori S, Ybarra N, Musial TF, Buss EW, Richter H, Oh MM, Nicholson DA, Disterhoft JF (2015) Aging-related hyperexcitability in CA3 pyramidal neurons is mediated by enhanced A-type $\mathrm{K}+$ channel function and expression. J Neurosci 35:13206-13218. CrossRef Medline

Sirota A, Montgomery S, Fujisawa S, Isomura Y, Zugaro M, Buzsáki G (2008) Entrainment of neocortical neurons and gamma oscillations by the hippocampal theta rhythm. Neuron 60:683-697. CrossRef Medline

Spiegel AM, Koh MT, Vogt NM, Rapp PR, Gallagher M (2013) Hilar interneuron vulnerability distinguishes aged rats with memory impairment. J Comp Neurol 521:3508-3523. CrossRef Medline 
Stark E, Abeles M (2009) Unbiased estimation of precise temporal correlations between spike trains. J Neurosci Methods 179:90-100. CrossRef Medline

Thomé A, Gray DT, Erickson CA, Lipa P, Barnes CA (2016) Memory impairment in aged primates is associated with region-specific network dysfunction. Mol Psychiatry 21:1257-1262. CrossRef Medline

Unal G, Apergis-Schoute J, Paré D (2012) Associative properties of the perirhinal network. Cereb Cortex 22:1318-1332. CrossRef Medline

Warburton EC, Glover CP, Massey PV, Wan H, Johnson B, Bienemann A, Deuschle U, Kew JN, Aggleton JP, Bashir ZI, Uney J, Brown MW (2005) cAMP responsive element-binding protein phosphorylation is necessary for perirhinal long-term potentiation and recognition memory. J Neurosci 25:6296-6303. CrossRef Medline

Westerink RH, Beekwilder JP, Wadman WJ (2012) Differential alterations of synaptic plasticity in dentate gyrus and CA1 hippocampal area of calbindin-D28K knockout mice. Brain Res 1450:1-10. CrossRef Medline

Wilson I, Ikonen S, Gallagher M, Eichenbaum H, Tanila H (2005) Age- associated alterations in place cells are subregion specific. J Neurosci 25: 6877-6886. CrossRef Medline

Wilson MA, McNaughton BL (1993) Dynamics of the hippocampal ensemble code for space. Science 261:1055-1058. CrossRef Medline

Wilson MA, McNaughton BL (1994) Reactivation of hippocampal ensemble memories during sleep. Science 265:676-679. CrossRef Medline

Winters BD, Bussey TJ (2005) Glutamate receptors in perirhinal cortex mediate encoding, retrieval, and consolidation of object recognition memory. J Neurosci 25:4243-4251. CrossRef Medline

Yassa MA, Mattfeld AT, Stark SM, Stark CE (2011a) Age-related memory deficits linked to circuit-specific disruptions in the hippocampus. Proc Natl Acad Sci U S A 108:8873-8878. CrossRef Medline

Yassa MA, Lacy JW, Stark SM, Albert MS, Gallagher M, Stark CE (2011b) Pattern separation deficits associated with increased hippocampal CA3 and dentate gyrus activity in nondemented older adults. Hippocampus 21:968-979. CrossRef Medline

Young BJ, Otto T, Fox GD, Eichenbaum H (1997) Memory representation within the parahippocampal region. J Neurosci 17:5183-5195. Medline 